\section{IN SEARCH OF THE TALKATIVE PUBLIC: MEDIA, DELIBERATIVE DEMOCRACY AND CIVIC CULTURE}

PETER DAHLGREN

\begin{abstract}
Theories of democracy consider communicative interaction among citizens central. In recent years the idea of deliberative democracy has galvanised elements of political theory with perspectives on communication.

This concept emerges to a large extent from the Habermasian trajectory and links currents from theories of civil society and citizenship. It has thus a rather forceful normative dimension. However, there are difficulties; and the aim of the article is to probe the notion of deliberative democracy by framing it in ways that may render it more useful for both theoretical and empirical work. The article begins with a quick interpretation of the theoretical background. From there the author discusses some current issues of conceptualisation, in particular if such talk should be seen as a part of everyday conversation or a special mode of interaction. These definitional issues set the stage for an examination of two recent empirical contributions. In the final section, the article attempts to situate deliberative democracy within an analytic framework of civic culture. Deliberative democracy, or more simply, discussion, becomes one of six dimensions of civic
\end{abstract}

culture.
Peter Dahlgren is Professor of Media and Communication Studies at Lund University, email: peter.dahlgren@soc.lu.se. 
Theories of democracy have always treated communicative interaction among citizens as a central element. Talk among citizens is seen as fundamental to - and an expression of - their participation. Contemporary normative versions of modern representative democratic vary in their views of how much citizen participation is desirable, as well as how much can actually be expected. Elite theories, for example, tend to assume a low level of civic engagement, and citizen's talk thus does not command a very privileged position. Other orientations underscore democracy's fundamental participatory character and argue for the promotion of civic engagement. Talk is seen as constitutive of publics, which is both morally and functionally vital for democracy.

It is within these latter circles that we find the coalescence of the idea of deliberative democracy, galvanising elements of political theory with perspectives on communication. The impact of Habermas and those working within his theoretical horizon have had a major impact in shaping the idea of deliberative democracy; it follows the traditional notions of the public sphere and becomes extended in Habermas' investigations into communicative rationality. There are, however, inputs from other traditions as well, which help frame the notion of the talkative public. Specific currents within theories of civil society and citizenship, for example, articulate neatly with the Habermasian trajectory, as they more or less flow together toward the estuary of deliberative democracy.

The forcefulness of these normative efforts suggests, at some level, a degree of optimism or faith in the democratic project. One could, alternatively, begin a discussion about deliberative democracy with a negative, pessimistic tone and paraphrase an old adage by saying: seldom have so many been spending so much energy theorising a phenomenon that is so small. The way the real world has been working lately might well give credence to the accusation that the primary site of deliberative democracy is in the heads of well-meaning but nad've theorists. Social and political trends over the past decade have given rise to an established lament that includes the stagnation of formal political systems, declines in traditional forms of political involvement, declines in party loyalty, growing symptoms of public cynicism, the increasing displacement of civic discourses in the media with economist and consumerist ones, the increasing fragmentation of publics, negative consequences of conglomerisation, and commercialisation of the media.

We witness also increased use of "spin": political public relations, strategic opinion polling, managed media visibility, hype, misinformation - in short the marketing model of politics and government with its arsenal of political "mood modifiers." ${ }^{11}$ The upshot of these developments, it is claimed, is that citizens are less engaged than ever, politics as a topic of discussion is rapidly nose-diving, and deliberative democracy is not a very helpful approach to understanding the contemporary world

Countering this unhappy narrative, however, is another set of by now familiar developments that suggest that the notion of deliberative democracy might still prove to be something more than a mantra among political navel-gazers. Such perspectives aim our attention toward new forms of political engagement and citizenship, indeed, even new definitions of what politics is about and new modes of political communication. Regardless of one's pessimism or optimism about either "old politics" or "new politics," at a minimum one would have to say that contemporary democracy finds itself in some kind of significant transition. Moreover, the 
older mass media and the newer interactive media are important factors entwined in this highly complicated situation (cf. Axford and Huggins 2001a; Bennett and Entman 2001). Clearly, the conditions and circumstances of communication play an important role in perpetuating but also problematising the established political patterns, as well as in facilitating the alternative developments.

Even if we posit that deliberative democracy, as a way of understanding the communicative dynamics of democracy at the level of citizen practices, is a prominently salient perspective, we are faced with difficulties, and we should not too easily shed a healthy scepticism. A major challenge is that the development of the concept within philosophical/theoretical discourses has not translated into any obvious utility for empirical research. In fact, there have been few empirical studies directly building upon the specific concept of deliberative democracy. My intention here is to probe the notion by framing it in ways that may render it more useful for contemporary theoretical and empirical work (though I'm sure that any "ultimate synthesis" still lies well beyond this presentation).

I begin with a very quick rendering of the theoretical background. This includes the Habermasian trajectory, as well as some currents from theories of civil society and citizenship. I then reflect what we might learn from the tradition of public opinion research. From there I discuss some current tensions in the conceptualisation of deliberative democracy, in particular if such talk should be seen as a part of everyday conversation or as a special mode of interaction defined and restricted by well-defined contexts. These definitional issues set the stage for an examination of two recent major empirical contributions. I then attempt to situate deliberative democracy within an analytic framework of civic culture that I am working on. ${ }^{2}$

\section{Theorising Deliberation: Great Expectations}

Deliberative democracy derives to a great extent from the work of Habermas and others intellectually close to him, but it is also embedded in a number of other theoretical discourses, which, not surprisingly, increasingly overlap and are becoming interwoven. Here I will thus briefly take up theories of civil society and citizenship, and the ongoing discussions about political disengagement. Each topic is quite massive in itself, with a very extensive literature; I can only touch upon some highlights here, but hopefully these short probes together will provide an adequate summary.

1. The Habermasian Trajectory. Habermas' early investigations from the 1960s about the public sphere had a major impact on thinking about media, publics, democracy, and the nature of political communication. These perspectives were debated, modified, and not least incorporated (albeit with modification) into the toolkit of many researchers who do not necessarily share the premises of Critical Theory. They continue to serve a general background for thinking about these matters. In the 1980s, Habermas began developing his ambitious theories about communicative rationality, as a part of an ambitious project striving to reconstruct the legacy of historical materialism, shifting the emphasis from labour to communication as the key to understanding societal self-creation. Obviously he did not generate this from scratch, but built upon and incorporated work from a number of directions, including theories of speech acts and psychological ego development. It is in this work where we find an important grounding for this trajectory of deliberative 
democracy. Many have discussed and further developed these ideas, relating them to theories of democracy, the practice of politics, subjectivity, and identity (cf. Benhabib 1996; Dryzek 1990; Elster 1998; Fishkin 1991; Guttman and Thompson 1996). There has also been a good deal of debate around the topic (cf. Sanders 1997).

We may take our point of departure in Habermas' work. Among his by now familiar conceptualisations is the distinction between system and life-world, the latter signifying a communicative mode characterised among other things by intersubjectivity and the open negotiation of norms and values. This scheme very complex in his writings - emphasises the potentiality of autonomy for the individual subject. That is, Habermas sees autonomy as a possibility, but never as something that is guaranteed. Indeed, part of the goal of his analysis is to highlight analytically (rather than empirically) the kinds of societal obstacles that hinder the lofty notion of "ideal speech situations." His emphasis on autonomy accentuates, in turn, the potential qualities of agency, self-reflection, critical judgement, the capacity for rational discussion, and not least, moral capacity.

Few would make the argument that these attributes are bad things; however, there has emerged a mini-publishing industry debating if, how, when, where, and by whom these qualities can be achieved via communication. Warren (1995) offers a handy overview of these developments, and offers the common critique that Habermas is somewhat locked into an excessively cognitive and rational view of the kind of communication that can - and even should - take place in the public sphere: talk among citizens does not resemble a philosophy seminar - nor should it. Warren (1995) and others make the case that while Habermas' emphasis on the development of the social subject via communication is of merit, his perspective ignores among other things important aspects about how psychological and psychoanalytic processes actually work in the human subject.

2. Civil Society: Grooming Citizens. Yet the processes whereby humans become social members remain important. Particularly in regard to the public sphere, the theme of how individuals become citizens, and by extension, how they collectively create a functioning democratic culture, is very much on the agenda - though not necessarily in all circles. Traditional liberal democratic theory, for example, largely postulates a fully mature citizen, who magically seems to spring out of a socio-cultural black box to play his or her role in democracy. Through the 1990s, and not in small part inspired by the political developments in Eastern Europe, theories of civil society have been very much on the upswing. There are a number of competing versions, but most seem at least compatible with the Habermasian trajectory of deliberative democracy (though by no means all proponents of civil society are followers of Habermas). A key text here is by Cohen and Arato (1992); a recent presentation of the civil society model particularly compatible with Critical Theory is found in Chambers (2002).

Civil society figures in both normative political philosophy (e.g. Walzer 1992; Sandel 1996) and social science (Janoski 1998; Putnam 2000). It is seen by many writers as the societal terrain between the state and economy. Merely such a rendering should suggest to us that there are obviously major conceptual and empirical dilemmas in defining civil society and its boundaries, as well as difficulties in classifying which of the many forms of collective activity/association/organisation in late modern society fall inside or outside those boundaries. Yet the main thrust 
here is a neo-Tocquevillian strand of optimistic thinking that posits that a healthy liberal democracy needs a robust domain of associational interaction. (The theory tends to ignore, however, "illiberal" and anti-democratic manifestations, such as racist and neo-fascist groups.) The argument is that such interaction helps individuals to develop socially, to shape their identities, to foster values suitable for democracy, and to learn to deal with conflict in productive ways. Civil society serves as training ground that "grooms" citizens, preparing them for civic participation and political engagement (we should note that the boundary between the civic and the political remains conceptually open).

Signs of ill-health within Western civil society have set off alarm bells in recent years; the decline in participation in civil society signals an impending erosion in democracy and is associated with the decline in political engagement. Putnam (2000) makes this case forcefully; his "bowling alone" metaphor captures not least the lack of communicative interaction among citizens. One of his arguments is that the decline in civic involvement results in a diminished "social capital" among citizens - which includes not least a reduction in communicative competencies (a view that has elicited much debate; cf. Edwards, Foley and Diani 2001). With increased fragmentation and atomisation follows a decline in social trust, which further inhibits participation. Putnam and others look to the socio-cultural landscape for explanations - and find for example, the dumbing-down effects and monopolisation of time that is associated with the new media culture. Others, like Cohen and Arato (1992), emphasise the role of the state, social and economic policies, and legal frameworks in shaping the character of civil society, thereby framing the question in more explicit political terms. While writing earlier and from a different tradition, Sennett's (1977) analysis of socio-historical decline of publicness in American culture is certainly relevant in this regard.

The Habermasian perspective sees civil society as the institutionalised setting of the life-world, and tends to link up the notion of the public sphere with that of civil society, underscoring its fundamental communicative character. In today's world, of course, the public communicative space for citizen talk in the public sphere/civil society consists of a vast, sprawling social field of almost infinite variety, criss-crossed by the media and encompassing many different forms of associations and networks, communicative contexts and styles, cultural frameworks, and power relationships. Thus, what kind of talk takes place between whom, how, when, and where within civil society are questions whose answers reside in the forcefield between macro structural/systemic factors and micro interactional dynamics.

3. Citizenship: Agency and Identity. This dual perspective of structure and agency carries over into modern theories of citizenship, particularly with those within the political philosophy of civic republicanism, which van Gunsteren (1998) calls neo-republicanism. This normative view is generally more directly associated with deliberative democracy than its two competitors, liberalism and communitarianism (though I share Beiner's view (1995) that any contemporary theory of democracy must acknowledge the productive interplay between the three). I cannot touch upon all the relevant traditions within several disciplines that have addressed citizenship, but for my purposes here it can suffice to stress that there are staunch strands of thought that go beyond the legal-formal conceptions of citizenship and lead us towards the ideal of the talking public. In the post-war era, writings of T. H. 
Marshall and others articulated the legal notions with social welfare perspectives, arguing basically that if minimal social conditions are not met, people will be unable to function in their role as citizens. This injection of the notion of citizen with a social actor dimension has continued. Based on cultural theory (e.g. Preston 1997; Isin and Wood 1999) as well as political philosophy (e.g. Clarke 1996; Mouffe 1993), these contributions have highlighted the dimension of identity as a key to understanding citizenship as a mode of social agency.

One of the hallmarks of late modern society is the emergence of the self as a reflexive project, an ongoing process of the shaping and reshaping of identity, in response to the multiple sets social forces, cultural currents and personal contexts encountered by individuals. In our daily lives we operate in a multitude of different "worlds" or realities; we carry within us different sets of knowledge, assumptions, rules and roles for different circumstances. People's identities as citizens (however defined) become actualised in relation to their sense of belonging to social collectivities and to their perceived possibilities for participating in societal development.

To which collectivities do we or might we want to belong? Citizenship has traditionally been associated with the nation-state, but increasingly debates about citizenship refer to a variety of entities. The neighbourhood, the city, associations and organisations of civil society, the region, even global society, are invoked. Within diasporic communities many people experience multiple loyalties, multiple identities, and increasingly even insist on multiple citizenship. In theoretic terms, citizenship, then, is not just a formal issue, but also one of self-creation, through communicative means. Yet the formal side of citizenship - backed up by guarantees of rights and entitlements, must not be ignored. People's identity of citizenship is not merely a subjective matter: there are a range of mechanisms of inclusion and exclusion that operate in different domains. Democratic membership and participation cannot function in the absence of institutional structures - legal, social, economic, cultural - that can solidify citizenship in the respective domains, an observation that connects with civil society's dependence on structural guarantees.

The Habermasian trajectory, perspectives from civil society, and contemporary theories of citizenship accentuate the possible and express an Enlightenment confidence. At the same time, they clearly can be used in a critical and constructive vein: as normative ideals, they can be mobilised to pinpoint the inadequacies of present conditions. Yet such discussions tend to remain at a rather lofty level. As deliberative democracy begins to move in the direction of the empirical, a basic question emerges: What kind of talk are we talking about?

\section{Definitions: What Kind of Talk?}

It is common sense that "talk is a good thing." (Here I disregard the specific cases where a greater good might be obtained by keeping one's mouth shut.) Talk has also associated with democracy and opinion formation, long before the Habermasian trajectory appeared. By talking to each other, citizens shape their opinions and thus generate the collective will, that then has some sort of impact on policy.

However, already in the early decades of the twentieth century, this faith in the collective good sense that emerges from the discursive interaction of citizens was called into question, most vividly by Walter Lippmann (1922) and especially via his debates with John Dewey (1954/1923). Lippmann emphasised not least an episte- 
mological problem: the media can only offer imperfect renderings of the world, and therefore citizens even under the best of circumstances only generate approximations in their heads of the world beyond their face-to-face realities. Thus, even if talk among citizens is a means of arriving at a collective will, there is a basic problem of knowledge and competence. Lippmann's conclusions tended to downplay the significance of this talk, whereas Dewey (1954/1923) emphasised its importance.

Dewey did not disregard the competence problem, but he chose to underscore the importance of civic engagement, which starts with talk. In his view, the lack of participatory communication is at the core of the dilemmas of modern democracy; the solution is to be found in enhanced civic interaction and involvement. Moreover, he saw such civic participation as beneficial for the individual, helping to promote his or her social development. Thus, for Dewey this talk places a large responsibility on the individual citizen and on the collective citizenry, but at the same time it is decidedly beneficial for both.

This line of disagreement continues until the present day. The argument accelerates with claims that democratic deliberation not only enhances democracy, but is also a cure for a variety of social ills, including a flagging sense of community and social underdevelopment, which takes us back to the civil society argument (cf. Walzer 1992). Some enthusiasts get a bit overheated at times and insist that the individual can only achieve his or her full human potential by participating in such talk. The benefits of civic and political interaction are seen as surpassing even those of the private domain of family and friends, or occupation: a failure to participate in political discourse would leave one a "radically incomplete and stunted being" (Oldfield 1990, quoted in Kymlicka and Norman 1995, 293).

1. Political Discussion vs. Social Conversation. Even if the majority of people in Western democracies somehow seem to live meaningful lives by following a different game plan - and most theorists do avoid such excesses - contemporary views about citizen talk at times thematise precisely this relationship between "political" and "non-political" talk, raising the question of definitions. A dominant position is found in Barber (1984; 1998), a leading proponent of what he terms "strong democracy" (which corresponds to the vigorous civic republican view). He asserts that even if citizens' interaction may be wanting in terms of deep knowledge and well-thought out opinions, it is crucial for maintaining a sense of collective civic identity and for generating a collective will. Citizen engagement is fundamental for democracy, and it begins with talk. The looseness, open-endedness of everyday talk, its creativity, potential for empathy and affective elements, are indispensable for the vitality of democratic politics. Similarly, Bohman $(1996,145)$ sees citizen talk as important for maintaining "a constant and vibrant interaction among cultures and sub-politics in a larger sphere of common citizenship." In his view, the character of civic talk is dynamic and open-ended, and not least reflexive: self-creation takes place in part via civic participation (a perspective that prefigures what I will discuss as civic culture later).

The alternative view was re-launched when Schudson (1997) made the case that "conversation is not the soul of democracy." His point is that "conversation" is basically about sociability. Political discussion, on the other hand, is about solving problems, finding solutions to conflicts; it is purposive, goal-oriented. Democratic deliberation is not "spontaneous"; rather it is civil, public, and not even necessarily 
egalitarian. It opens up the door for social discomfort, seemingly the opposite of what is usually intended with conversation. Warren (1996) makes a similar argument from a somewhat different angle when he calls into question what he sees as one of the basic (but usually tacit) assumptions of the "radical democracy" theory (which usually manifests some version of civic republicanism). He challenges the idea that political engagement is at bottom attractive, something that people would freely choose if only the opportunity would present itself. Warren sees this as romantic dogma, or at best wishful thinking. Most avoid political discussion (and engagement more generally) to avoid what he terms the social groundlessness of political space, withal the anxieties and uncertainties that follow from it.

If theory is too blindfolded by wishful thinking, it will inevitably begin tripping over the furniture and walking into walls. Schudson, Warren, and others sharing their views certainly score two points for basic sociological realism. Yes, political discussion can be uncomfortable and awkward, and it is perfectly reasonable that most people in most circumstances tend to shy away from it. The attractions of deliberative democracy largely pale in comparison to any number of other activities that quickly come to mind, even if we note many exceptions to this pattern, e.g., obvious social functions that political talk can have for single issue groups, social movements, or voluntary civic work. However, what we need to be more precise about is what kind of talk is being referred to. What definitions are at work? It seems that Schudson et al. are operating with an understanding of political discussion that is quite bounded, indeed, one might call it "formal." Political discussion thus is associated with a specific kind of context; it becomes situationally distinct from other modes of talk. One can certainly operate with this kind of definition. Empirically, it will capture certain kinds of citizen interaction that are largely clearly defined in - and by - their contexts.

Barber, Walzer and others have a different point of departure. While (I assume) they would acknowledge that formal contexts of the kind that Schudson has in mind do exist, they look beyond these delimited settings. They emphasise instead the permeability of contexts, the messiness and unpredictability of everyday talk, in order to put forth the view that "the political," and thus the individual's role as citizen, is never a priori given, but can emerge in various ways within informal everyday speech. It is via meandering and in part never fully predictable talk that the political can be generated, that the links between the personal and the political can be established.

2. Agonistic Performance and "the Political." In a similar vein, but perhaps at a higher level of abstraction, Mouffe (1999), an exponent of post-Marxian radical democracy, criticises the notion of deliberative democracy as it appears in the Habermasian tradition. Mobilising Wittgenstein's notion of language games, she makes the point that the very idea of neutral or rational dialogue is untenable. For Wittgenstein, agreement on language necessitates agreement on forms of life. This in turn projects one inevitably into issues of power and antagonism. Inevitably, rhetoric, persuasion, compromise - rather than rational consensus - prevail. There is a performative emphasis here, rather than a demand for "authenticity" in political discussion that has certain echoes of Arendt.

The word agonist comes from Greek and signifies someone who is engaged in a struggle. Agonistic democracy is not predicated on Habermasian consensus, but 
rather on argument, performance, and the hope that one can at least reach compromise. In Mouffe's perspective, the goal is not to avoid conflict - on the contrary, she assumes that conflict is a built-in potential in all social relations and in all kinds of talk. Rather, her vision is that antagonism be displaced by what she calls agonistic pluralism, a political culture where the forms of interaction and power are compatible with democratic values, where conflict takes place between "adversaries" rather than "enemies." Operating in Mouffe's work is also a notion of the subject who has a more post-modern profile than normally found in political science or in the Habermasian currents. In those traditions, citizens appear as rather neat and trim, with integrated and transparent egos. Mouffe's citizen is characterised by plural subjectivity; being a "citizen" is but one of many possible subject positions (she has also written a good deal on citizenship theory and identity, cf. Mouffe 1993). Still more relevant, Mouffe's vision of shared democratic rules of the game, a minimal unifying allegiance to democratic certain values and procedures, points us toward the theme of civic culture that I address below.

To return for the moment, however, to the theme of citizen talk and the issue of bounded, formal discussion vs. the more free rolling, untidy character of informal everyday conversation, Mouffe makes a relevant distinction between politics and "the political":

By "the political" I refer to the dimension of antagonism that is inherent in all human society, antagonism that can take many forms and can emerge in diverse social relations. "Politics," on the other hand, refers to the ensemble of practices, discourses and institutions that seek to establish a certain order and to organize human coexistence in conditions that are always potentially conflictual because they are affected by the dimension of "the political" (Mouffe 1999, 754).

If we try now to connect this with modes of discussion, it would seem that Schudson, Warren, Habermas and those who hold a similar position basically have in mind, talk about politics, as Mouffe uses the term, whereas Barber, Walzer and others accentuate the processes by which the ever-present potential of the political can manifest itself - and may then veer talk into the realm of politics. If the former view may be more handy to deal with empirically, given its boundedness, it seems at this point that the alternative allows for more avenues for interesting investigation since it keeps open the border-crossing between the political and the nonpolitical. Talk can take many unforeseen twists and turns and different subjective dimensions - including civic ones - may be activated. The road is thus in principle open between the domains of the non-political and the political, which heightens precisely the odds that new topics will become political and thereby make an impact on politics - both traditional "old-style" politics and the newer forms of informal, extra-parliamentarian politics.

This line of thought links up with other conceptual schemes, even if the vocabulary may vary somewhat. Beck $(1997,133)$, for example, distinguishes between the "rule-directed" and "rule-altering" politics. The rule-directed politics may be creative and nonconformist, but it operates within the constraints and logic of the prevailing, formal political system. Rule-altering politics, on the other hand, can be seen as a "politics of politics," challenging the rules of the game, the prevailing definitions, or dominant agenda. Beck suggests that rule-altering politics embod- 
ies a strong reflexive dimension, which I interpret to mean that it invites citizens to see themselves as not only political actors acting out given roles and agendas, but as social actors who create and define both themselves and what politics is about.

If we pull together these reflections, it would seem that the notion of "deliberation," while normatively central to democracy and suitable for depicting forms of discussion in certain settings, is actually too narrow to capture the broader kind of civic discussion that I have refereed to. It pertains to specialised, formal mode of discourse, and thus we would do better, in the empirical world, to think about "discussion" or "talk," which can encompass many different kinds of communicative interaction.

We have reached a point in this discussion here where we need to touch base with some empirical work. I have charted some currents in the literature about deliberative democracy, emphasising in particular the definitional tension between bounded, formal discussion and unstructured flows of everyday conversation. But what does the empirical reality look like? How does deliberative democracy proceed in practice?

\section{In the Real World: Look Who's Talking}

The idea of deliberative democracy has emerged as a rather theory-heavy notion. Its advocates talk a lot about the talk of citizens, but they have not been in any hurry to provide much empirical data. There are, however, studies appearing. Certainly the nature of political discussion on the Internet is a growing topic, though findings tend not to be very encouraging for deliberative democracy (cf. Wilhelm 2000). ${ }^{3}$ In this section, I will look at two major research studies in the U.S. that have taken the step of examining citizens talk against the backdrop of the traditional mass media. First, though, I will make a short detour through the theme of public opinion research, considering especially its conception of knowledge

1. Opinion and Knowledge. The idea of deliberative democracy thus builds upon the themes of democracy and citizens' communicative interaction in civil society/public spheres, and emphasises the formation of political will. One might think that there would consequently exist a formidable magnetic field between it and the tradition of public opinion research. Such - understandably, but also unfortunately - is not the case. The two move in different circles and seem hardly to be on speaking terms. Without rehearsing all the methodological and conceptual issues that still today hover around opinion research, one can concur with Splichal (1999) who finds that in the course of the twentieth century, interest in the social theoretic side of opinion formation tends to decline as the techniques of measurement grow in sophistication. Opinion research has tended to work with a downsized epistemological toolkit that is very delimited in the kinds of constructions it can make.

Opinion studies cling to the old dualism of facts and values, which they recycle in terms of knowledge and opinion. This is sometimes formulated as "what we think is distinct from what we think about" (a premise especially prominent in the agenda-setting variant of opinion studies). Opinion becomes operationalized as the views of individuals, atomised utterances to be statistically aggregated and analysed. The ethnographic legacy of the Chicago School was eradicated from the emerging practices of opinion polling fairly early on. Even the relatively late con- 
tribution to interactional perspectives offered by the two-step flow model in the mid-fifties by Lazarsfeld and Katz (1955) of the Columbia School seems marginalised in much of today's opinion research.

The notion of knowledge found in the toolkit is stunningly value-free. The actual empirical charting of political knowledge has been rapidly diminishing in the practices of opinion research, replaced at best with questions about what respondents think they know (Lewis 2001, 109). The "uninformed citizen," the low level of civic competence, is something that is problematic for democracy to take up in serious, public ways. It is also a practical problem, because the unease that may be created during interviews by focusing on knowledge may put at risk the smooth completion of the interviews. Yet even when political knowledge is empirically studied in opinion research, it is mostly approached as simple, factual awareness. That knowledge, opinion, as well as knowledge frameworks, assumptions, and beliefs tend to be discursively interrelated, socially constructed, context-bound, and potentially ideological, is not something that has troubled opinion research.

Such dimensions are certainly well within the horizons of the discursive democracy perspective, though largely addressed at the theoretical level. This scarcity of empirical materials must be confronted as a problem. Elucidating deliberative democracy even from quantitative angles would be important. At some point the normative concerns of deliberative democracy need to grapple with the empirical issues of large, complex societies: What is actually going on? It needs to connect with kinds of processes that we would call public opinion (at least until some better concept comes along, and I wouldn't hold my breath for that).

Despite the scepticism we might have toward opinion studies, it would be misguided to simply dismiss all such research. Such studies can still tell us interesting things. Traditionally, the overall view of the public that emerges from public opinion studies has not been very encouraging for theorists of participatory democracy. If we look closely, we see that the large majority of citizens in Western democracies are not very interested in political matters, at least as commonly defined. What is sometimes called "the active public" - those who are in some ways manage to sustain a genuine engagement in public issues - weighs in at about 15 percent (U.S. figures) and is over-represented by various elite elements of the population. What are called "issue publics," can offer some consolation: these may engage larger numbers of citizens, recruited from a broader background at given moments, but of course they are characterised by flux and much variation. If it is "the public" or many "publics" that actually do deliberative democracy, it does not hurt (even if it may be disappointing) to have some contours of the collectivities we have in mind.

We need to keep in mind, though, that to refer to "the public" inevitably involves some element of mythic thought. It does exist somehow and somewhere, yet we can never have full knowledge of it. At the same time we operate "as if" we could. Peters (1995) sees the public in part as an effect of representation: a constructed entity, whose ultimate reality evades realism's efforts to render it immediately accessible to us - a quality that is no less true for "democracy," one might add. However, the point here is not to imply that there exists some viable empirical alternative to the constructions of representation. Most of us, for example, have now managed to make peace with the idea that "the nation" is an "imagined community" - probably because it obviously still seems to work despite this attribu- 
tion. Rather, the point here is to urge for a sense of modesty in the kinds of knowledge claims we can make about "the public."

It would be unproductive to set up some kind of artificial confrontation between public opinion research and the notion of deliberative democracy; pie throwing won't help. If we lean towards not taking at face value all the statistical results that opinion research offers, this field still can stimulate us to look behind the figures and continue wrestle with this frustratingly elusive area in deeper ways, as a number of scholars are doing (cf. Splichal 1999; 2001; Glasser and Solomon 1995; Lewis 2001). And gradually, perhaps, we will find more and better ways to empirically investigate deliberative democracy. I turn now to the two studies.

2. Talking Politics. Kim (1997), Kim, Wyatt and Katz (1999), and Wyatt, Katz and Kim (2000) are complementary works that derive from various constellations of co-operation around the same project, which is based on extensive telephone interviews with a sample of over 1000 citizens in all fifty US states. ${ }^{4}$ Eliasoph (1998) is an ethnographic analysis of several civic and political groups and examines how political talk is socially accomplished - and largely repressed. What makes for an interesting comparison is that both projects set out to empirically study deliberative democracy in practice, and they arrive at very different conclusions. KKW are encouraged by their findings; their results should cheer up those who might have the impression that citizens do not engage much in political talk. Eliasoph, on the other hand, is both surprised and troubled by what she finds, and she does not try to hide her discouragement.

The theoretic point of departure for KKW is an alignment with the position of fluid, unbounded, informal conversation as the essence of deliberative democracy; they explicitly distance themselves from the position of Schudson and likeminded colleagues. Kim, Wyatt and Katz define deliberative democracy as

a process whereby citizens voluntarily and freely participate in discussions on public issues. It is a discursive system where citizens share information about public affairs, talk politics, form opinions, and participate in political processes... The whole system is discursive inasmuch as each category of deliberation - sharing information, talking about it, forming opinions, and participating - possesses characteristics of "discourse" and "communicative action" $(1999,361)$.

This four-stage model - media exposure, talking about media output, opinion formation, and political participation - is based on Katz's (1992) appropriation of Tarde's studies of opinion. The scheme makes good sense. Even if one can raise questions here - such as about the origins of political discussion that does not derive from the agendas set by the media - the scheme highlights political talk as a link in a processual chain framed by traditional notions of opinion formation and citizen involvement.

Their survey project focused on nine content-specific topics within current affairs. The respondents were asked to estimate the extent to which they engaged in talk about these topics, under what circumstances, and how comfortable they felt about it. We should note, thus, that though the project presents itself as a study of deliberative democracy, it does not analyse any actual talk, but rather asks respondents to answer questions about their political talk. I won't go into detailed results, 
but KKW use phrases such as "reasonable levels" to characterise the frequencies of political conversation. They portray a relatively talkative citizenry.

They also find that news media use is closely associated with frequency of political conversation in daily life, both in general and issue-specific. The willingness to argue is influenced partly by majority perceptions (ŕla the spiral of silence theory of Noelle Neumann 1993), but more so by news media use and the frequency of political talk. News media use and political conversation have positive effects on certain measures of the quality of opinions (e.g. character of argumentation, consideration of alternative opinions); more talk leads to better developed opinions. News media use and political conversation are closely associated with participatory activities, but more so with following campaigns within the formal political system than with what they call "complaining" (sic) type of participation, which is largely the domain of younger and non-White citizens.

We can notice that the theme of media attention yielding a high payoff in terms of political activity (at least of the formal kind) has a long tradition behind it (though this may be changing, given not least the direction that media is taking, as I discuss below). A recent contribution to this theme is Milner's (2001) study, which makes national comparisons and finds that those nations where citizens pay high attention to journalism and where public service (the quality factor) is still viable tend to have higher voter turnouts.

In Wyatt, Katz and Kim (2000), the authors report that for their respondents, home is the site where most political conversation takes place, i.e. the most private space has become the most frequent site of the public sphere. The workplace is reported as the second most common site for citizen interaction. These are truly significant findings; we might have suspected this for a while, now, given all we know about the public sphere and the processes of privatisation, and so on, yet it is very helpful to have this confirmed empirically. That the dominant site of civic talk is now the home has of course quite profound implications for any theory about the public sphere, but the authors do explore this line of thought very far. Given that the respondents claim that they talk fairly free about politics - in the context of informal conversation - KKW conclude that informal political conversation seems to be interwoven with the fabric of everyday talk. We see here a robust public sphere/civil society populated by civic republicanist citizens - though it would be interesting if they had pursued at the theoretical level the implications of this homebased public sphere. KKW mention the very different kinds of findings in the work of, for example, Noelle-Neumann (1993) and Eliasoph (1998); these variances are not discussed, but instead their studies end on the positive portrait of civic discussion that emerges from their work.

3. Repressing Politics. Eliasoph (1998) sets a very different kind of project for herself. She spent two and a half years in the field ethnographically studying three sorts of civic groups: volunteer, recreational, and activist. I certainly cannot here do justice to the richness of her work, but will just present some of her key points. Using among other things Goffman's scheme of front-stage/back-stage, she finds that the citizens in these groups do talk about politics, but they do so largely within quite particular contexts. Basically, these citizens tend to enact an odd reversal of the public/private distinction: in the front-stage settings within the groups, and not least where member of activist groups are addressing the media or larger pub- 
lic, there is a strong tendency to avoid speaking about politics. Yet, after the meetings, in private, when microphones are turned off, the talk can become very political.

On the one hand, Eliasoph means that within some of the groups there is the assumption that politics is divisive, painful, and generally to be avoided since it puts sociability at risk. Schudson et al get some empirical validation for their views about the social awkwardness of political talk. Another theme is that people, when talking about politics, will often emphasise the local, close-to-home issues. They do this to the point of even repressing for themselves the connections they obviously make between the local and larger contexts. The issue of efficacy is obviously (though unconsciously) at work: defining problems at too grand a level can readily evoke feelings of powerlessness; it is best to delimit challenges so they seem do-able.

But there is more. Eliasoph goes on to show how there seem to be tacit cultural mechanisms at work that hinder the expression of any kind of ideals reflecting a public spirit and having to do with the common good, general welfare, and so on, in front-stage, i.e., public contexts. Such pronouncements are simply not treated as credible. Thus, for example, some of her ecological activists package their public arguments as the voice of "concerned mothers" worrying about the health and future of their children, rather than as spokespeople who demand a better environment for the sake of everyone living in the endangered area. It is simply assumed that all activism is based on immediate self-interest.

Although she incorporates such obstacles as the spatial parameters of the suburban-sprawl environment (where she did her study) and how this can inhibit political communication among citizens, her main argument is cultural: politics is perceived to be expressions of self-interest, and such expression is generally minimised to avoid socially uncomfortable tensions or reduced credibility. The backstage becomes the site for open political expression; in front-stage, such talk risks being dismissed as either cynical or nad've, or within the groups' own meetings, of endangering an often fragile yet valued sense of community. She sees this as a process of "political evaporation," which she summarises as follows:

the farther backstage the context, the more public-spirited conversation was possible. ... he farther the voice from a whisper, and the larger the audience, the less eager were speakers to ponder issues of justice and the common good, to present historical or institutional analyses, to criticize institutions, to invite debate, to speak in a publicly minded way (Eliasoph 1998, 255).

Not surprisingly, she concludes that her findings do not provide a jolly prognosis for the public sphere. It is interesting that her study puts on the agenda for deliberative democracy specifically, and the public sphere/civil society more generally, the issue of the cultural frameworks that shape interaction, the unspoken "rules" that define what kind of talk is appropriate (and not) in which kinds of situations. There are myriads of interactional settings, which may impact on political talk, and we cannot know if they all function similarly to the ones she investigated. But her work forces us to consider this dimension in any real-world approach top deliberative democracy.

KKW's study is based on "average" citizens, in the sense that they did not select people who were necessarily involved in any civic or political group. Keeping in 
mind that people tend to present themselves in a favourable light in interviews (even via "honest" self-deception), it would have been interesting (though quite impossible) to compare this with what they actually do. Such an angle would obviously require a research investment of a whole other magnitude. Yet clearly there is something of deep interest in the discussion patterns of U.S. citizens that this study captures. That Eliasoph and KKW arrive at different conclusions might of course be clarified to some extent by examining more deeply their respective assumptions, contexts, definitions, and methodologies, but that lies beyond this presentation. I will only note that the differences in their conclusions suggest that empirical investigation of deliberative democracy still has a mighty far to go.

One final point of comparison on a particular topic: KKW underscore the positive, catalytic role of the media, finding that media attention among their respondents tends to correlate with political engagement. Eliasoph, in a chapter devoted to an analysis of local journalism, observes that reporting is coloured by a systematic cynicism towards the fundamental values and procedures of democracy. She concludes that this journalism in effect works against citizen engagement, since activism would in that context appear as foolish. In short, this media output apparently contributes to the climate that sees public engagement as "silly and nad've" (cf. Gamson 2001 for findings that support the view of the media as a source of political disengagement). This downcast analysis follows in the footsteps of a long tradition of critical evaluation of the media and the public sphere. Obviously we cannot come to any simple and unified evaluation of mass media output (let alone the uses of interactive media), but this should remind us that at the very least, the media are decidedly not an unequivocally positive contribution to the public sphere or deliberative democracy. Research on this theme will have to be very focused and contextspecific, since sweeping generalisations will not be of much help at this point.

\section{Minimal Criteria, Modest Hopes: Civic Culture}

In trying to pull together the theoretical background and the small empirical evidence in order to develop a more useful analytic frame for deliberative democracy, it strikes me that there is a hole in the literature. It either talks about normative perspectives of democracy, such as modes of citizenship, or it theorises communication in the abstract. Alternatively, it addresses social institutions, such as the media and the public sphere. What seems to be largely absent is a perspective that aims more at the practical features and dynamics of engagement in terms of culture and meaning, and that situates civic talk or discussion as part of a larger set of what we might see as "cultural prerequisites" for political engagement. In other words, the framework of civic culture emerges out of a need to see and understand discussion among citizens as something embedded within other cultural dimensions, operating in dynamic interaction with them.

To begin to develop such an analytic frame - which I can of course only briefly sketch here but will further develop in forthcoming texts - I take a sort of "cultural turn" and propose that we consider the notion of civic culture. I hasten to add that this is not the Parsonian civic culture concept developed within political science during the 1960s. That version tended to be systemic, psychologistic and reductionist; what I have in mind is a civic culture that is, philosophically speaking, constructionist and materialist. Also, linking civic culture with some version of 
democratic theory means that we inevitably see it in a triple light, as the Swedish political scientist Lundquist (2001) argues. It has normative, empirical and a criti$\mathrm{cal} /$ constructive dimensions: What should the civic culture look like? What in fact does it look like today? What kinds of factors influence it? How can it be enhanced to further strengthen/deepen democracy?

The notion of civic culture points to the normative need for citizen engagement to make democracy work. Empirically, it looks at those features of the socio-cultural world that constitute everyday pre-conditions for democratic participation: in the institutions of civil society, engagement in the public sphere, and involvement in political activity broadly understood. These preconditions involve cultural attributes prevalent among citizens that can in various ways facilitate democratic life, (including the processes whereby the definitions of democratic life are defined and translated into politics). A civic culture is both strong and vulnerable: it generates the normative and cultural resources required for a functioning democracy, yet it sits precariously in the face of political and economic power (cf. the Habermasian notion of the life-world being colonised by the system). It can be shaped by citizens, but can also shape them; civic culture can serve to empower or disempower citizens.

If we begin to specify civic culture's structural, institutional prerequisites, we get a familiar textbook list that with constitutionalism at the top. This includes such seemingly mundane but ever so crucial elements such as the rule of law, democratic decision-making, the separation of powers (executive, legislature, judiciary), formal, universal/inclusive citizenship, individual rights such expression, assembly, association, religion, free, fair, recurring elections, and accessible and alternative sources of information. If these features are not working well, then civil society and deliberation among citizens are not likely to be in good shape, either. Social structure, institutional factors - not least the media - as well as patterns of interaction, all play a part in shaping it

I model civic culture as consisting of six basic parameters, most of which I am sure will be familiar in some way; my aim is to weave them together into an analytic whole. I present them as a list, but they should be understood as constituting a dynamic circuit of mutually reinforcing elements. Each parameter reflects a normative assumption, opens doors for empirical study, and should provide utility for critical analysis. In the real world of today I must underscore that we should set our sights for minimal thresholds... I will deal in turn with: values, affinity, knowledge, practices, identities, and discussion.

1. Civic Values. It should be underscored that values have to have their anchorings in everyday life; a political system will never achieve a democratic character is the world of the everyday reflects anti-democratic values. We can distinguish between substantive values such as equality, liberty, justice, solidarity, and procedural ones, like openness, reciprocity, discussion, responsibility/accountability, tolerance. However, just what are the best or real democratic values, and how they are to be applied, can of course be the grounds for serious dispute-and should be. This is precisely why the procedural norms and mechanisms take on extra importance. Resolution of conflict, striving for compromise in situations where consensus is impossible, is a key task for a democratic society and requires a commitment to the rules of the game. 
2. Civic Affinity. I have in mind a sense of commonality and trust, but something less ambitious than "community" - rather, a minimal sense among citizens in heterogeneous late modern societies that they belong to the same social and political entities, despite all other differences., and have to deal with each other to make it work, whether at the level of neighbourhood, nation state or the global arena. Conflicts become enacted between "adversaries" rather than "enemies"; grounded on a realisation among all groups of the mutual need to maintain democracy and adhere to its rules. Community of the more compelling kind, with strong affect, may (at best) also exist, but I am here deliberately avoiding a communitarian argument for a foundation for democratic society. A sense of civic commonality blurs into civic trust. Here too I envision a modest, minimal threshold. The arguments of Putnam (2000) about social capital and social trust are relevant here, even if his somewhat different approach (emphasis on social patterns rather than cultural meanings) makes it difficult to simply plug-in his position here as a neat puzzle piece.

3. Civic Knowledge. These have to do with relevant knowledge and with various abilities, especially communication skills. Knowledge, as I suggested above, is no simple matter, yet forms of reliable, referential cognisance of the social world is indispensable for the vitality of democracy (a position that I think can certainly be nuanced by recent postmodern philosophical reflections on referentiality and knowledge, but not entirely negated). Likewise, the capacities to deal communicatively in the socio-political world are pivotal. In regard to both knowledge and competencies, however, we must be very alert for the vast array of different forms and inflections that can exist between individuals and groups. Not least new media technologies and cultures can promote new modalities of thought and expression, new ways of knowing and of communicating. This on the one speaks to and for democratic pluralism, yet on the other hand we must be alert to the question of the efficacies of different modalities in the face of dominant power.

4. Civic Practices. Citizen talk and engagement must be embodied in concrete, recurring practices and their corresponding contexts. Individual, group, and larger collective practices - relevant for diverse situations - must have an element of the routine, of the taken for granted about them, if they are to be a part of a civic culture. Yet, civic culture must allow for the spontaneous, the one-off, the novel; in a sense, meta-rules for breaking the normal rules. Elections can be seen as a form of practice in this regard, but a civic culture requires many other practices, pertinent to many other circumstances. For example, how to hold a meeting, manage discussion, even how to argue, can be seen as important features of the life-world that have bearing on civic culture. The interaction among citizens is a cornerstone of the public sphere, and the kinds of established rules and etiquette that shape such interaction either promote the practices of public discussion or contribute to their evaporation, as Eliasoph (1998) clearly demonstrate. Across time, practices become traditions, and experience becomes collective memory; today's democracy needs to be able to refer to a past, without being locked in it. New practices and traditions can and must evolve to ensure that democracy does not stagnate.

5. Civic Identities. Here we return to the theme of people's subjective reality, their sense of democratic belonging and their self-definitions as potential participants (which, to reiterate, does not deny the importance of the formal, legal di- 
mensions). We should see the citizen component of late modern individuals as increasingly multidimensional and protean. Hybrid ethnicities, regionalisation, postcolonialism, the EU, issues of gender and sexual preference, etc. all impact on peoples' sense of their civic selves and their efficacy as citizens.

6. Civic Discussion. This takes us back to the starting point: the centrality of communicative interaction - talk - between citizens. This dimension is in some way an overarching one, one that embodies the others. Yet, I think it will prove productive to see it as a distinct dimension, functioning in reciprocity with the other dimensions of the circuit, being both shaped by and impacting on the other five.

Conceptually, civic culture is understood as the dynamic interrelation of these parameters; e.g., civic practices can enhance identities, which in turn may promote civic values and commonality. Negative developments are of course also possible (and many would no doubt claim that is precisely what we are presently experiencing). The media weave through civic culture in a tight way, both shaping and reflecting it. We can look at each parameter and analyse the media connections, for example, what values, sense of commonality, and implications for trust do we find in the mass media? How are interactive media helping to promote civic competencies and identities? If we position deliberative democracy in this framework, we can illuminate how talk/engagement give voice (or not) to specific values, which competencies are manifested in particular contexts, what kinds of practices foster/impede talk, as well as how does talk construct particular practices, and so on. If one adheres to the view that political talk among citizens is best understood as grounded in the informal flowing character of everyday speech rather than as a separate and distinct mode of discursive activity, the topic of the (usually tacit and taken for granted) distinctions between the political and the non-political, and the processes by which the definitional changes may impact on old and new politics moves to the fore. So too do the rules and etiquettes that steer such talk.

\section{Getting More Empirical}

If the analytic parameters of civil culture can provide a starting point for coming to grips with real-world deliberative democracy, we still need to go further in empirical specificity. The selection of the citizens to be studied has to be weighed carefully, perhaps taking into account dispersed actor-networks. Consideration of the sites, spaces and contexts of citizen talk evokes whole traditions of micro-sociology, especially if one approached from a grass-roots, bottom-up angle. There are also top-down situations: increasingly, governments at local, regional and national levels are arranging such events as on- and off-line citizen panels, telly-talk, focus groups, community forums, citizen juries, and consensus conferencing. While such efforts might be seen as part of government strategies within the market model of politics, there is no guarantee, as Axford and Huggins (2001b) argue, that such situations may not "backfire" and actually augment deliberative democracy, reflexivity and engagement.

There is also a range of questions having to do with the actual discursive character of citizen interaction in concrete situations, as Eliasoph (1998) underscores; N cultural codes, not least between different groups can become very important here. 
Mechanisms of discursive inclusion and exclusion need also to be addressed. Further, overarching ideological climates and mechanisms may come into play: currents of elitism, economism, consumptionism, cynicism, etc. may all impact of what gets said between whom, how it is said, and under what circumstances. The media's role here, as resource and symbolic environment, but also as communicative infrastructure (especially in regard to interactive media) needs to be situated squarely in any analysis.

A basic methodological challenge that sometimes arises in the investigation of any specific, situated phenomenon is to decide how far to cast the net to capture the larger context. For instance, in the analysis of TV-reception, the circulation of TV-derived meaning can potentially be the entire social field, as people's TV-inspired talk takes place in many contexts beyond the site of reception. Likewise, with deliberative democracy, any chosen site will have to be delimited from a potentially much larger social terrain.

The research horizon: so much to do, in so little time, with so little money...

\section{Notes:}

1. Bauman (1999) and Boggs (2000) represent recent and differing analysis of these developments from the left.

2. This presentation relates to other efforts where my recent efforts to probe the changing relationships between media, citizens, and democracy; cf. Dahlgren 1996, 2000a, 2000b, 2000c, 2001.

3. I can mention in this context new research initiatives concerning Internet-based global civic engagement centred at the University of Washington under Lance Bennett, available at www.engagedcitizen.org.

4. I will refer to the specific texts where necessary, but when treating their work collectively, I will label it "KKW" for ease of exposition.

\section{References:}

Axford, Barrie and Richard Huggins, eds. 2001a. New Media and Politics. London: Sage.

Axford, Barrie and Richard Huggins. 2001b. Public Opinion and Postmodern Populism: A Crisis of Democracy or the Transformation of Democratic Governance? In S. Splichal (ed.), Public Opinion \& Democracy: Vox Populi-Vox Dei?, 193-213. Cresskill, NJ: Hampton Press.

Barber, Benjamin. 1984. Strong Democracy: Participatory Politics for a New Age. Berkeley: University of California Press.

Barber, Benjamin. 1999. A Place for Us. New York: Hill and Wang.

Bauman, Zygmunt. 1999. In Search of Politics. Cambridge: Polity Press.

Beck, Ulrich. 1997. The Reinvention of Politics. Cambridge: Polity Press.

Beiner, Ronald. 1995. Introduction: Why Citizenship Constitutes a Theoretical Problem in the Last Decade of the Twentieth Century. In R. Beiner (ed.), Theorizing Citizenship, 1-28. Albany, NY: State University of New York Press.

Benhabib, Seyla, ed. 1996. Democracy and Difference. Princeton: Princeton University Press.

Bennett, W.Lance. 1998. The Uncivic Culture: Communication, Identity, and the Rise of Lifestyle Politics. Political Science and Politics 31, 741-761.

Bennett, W. Lance and Robert M. Entman, eds. 2001. Mediated Politics: Communication in the Future of Democracy. New York: Cambridge University Press.

Boggs, Carl. 2000. The End of Politics: Corporate Power and the Decline of the Public Sphere. New York: The Guilford Press.

Bohman, James. 1996. Public Deliberation: Pluralism, Complexity and Democracy. Cambridge, MA: MIT Press. 
Chambers, Simone. 2002. A Critical Theory of Civil Society. In S. Chambers and W. Kymlicka (eds.), Alternative Conceptions of Civil Society, 90-110. Princeton: Princeton University Press.

Clarke, Paul Barry. 1996. Deep Citizenship. London: Pluto.

Cohen, Jean L. and Andrew Arato. 1992. Civil Society and Political Theory. Cambridge, MA: MIT Press.

Dahlgren, Peter. 1996. Media Logic in Cyberspace: Repositioning Journalism and Its Publics. Javnost-The Public 3, 3, 59-72.

Dahlgren, Peter. 2000a. L'éspace publique et l'Internet. Réseaux 100, 157-186.

Dahlgren, Peter. 2000b. Media and Power in a Small Country: Sweden. In J. Curran and M. J. Park (eds.), De-Westernising Media Studies, 251-264. London: Routledge.

Dahlgren, Peter. 2000c. Media, Citizens and Civic Culture. In M. Gurevitch and J. Curran (eds.), Mass Media and Society, 3rd ed, 310-328. London: Edward Arnold.

Dahlgren, Peter. 2001. Media and the Transformation of Democracy. In B. Axford and R. Huggins (eds.), New Media and Politics, 64-88. London: Sage.

Dewey, John. 1954/1923. The Public and its Problems. Chicago: The Swallow Press.

Dryzek, John S. 1990. Discursive Democracy: Politics, Policy and Political Science. Cambridge: Cambridge University Press.

Edwards, Bob, Michael W. Foley, and Mario Diani, eds. 2001. Beyond Tocqueville: Civil Society and the Social Capital Debate in Comparative Perspective. Hanover, NH: University Press of New England.

Eliasoph, Nina. 1998. Avoiding Politics: How Americans Produce Apathy in Everyday Life. Cambridge: Cambridge University Press.

Ellison, Nick. 2000. Civic-Subjects or Civic-Agents? The Structure-Agency Debate in Late Modern Perspective. Theory, Culture \& Society 17, 148-156.

Elster, Jon, ed. 1998. Deliberative Democracy. Cambridge: Cambridge University Press.

Fishkin, James S. 1991. Democracy and Deliberation. New Haven: Yale University Press.

Gamson,William A. 2001. Promoting Political Engagement. In L. Bennett and R. Entman (eds.), Mediated Politics: Communication and the Future of Democracy, 56-74. New York: Cambridge University Press.

Glasser, Theodore L. and Charles T. Salmon, eds. 1995. Public Opinion and the Communication of Consent. New York: Guilford Press.

van Gunsteren, Herman A. 1998. A Theory of Citizenship. Boulder: Westview Press.

Guttman, Amy and Dennis Thompson, eds. 1996. Democracy and Disagreement. Cambridge, MA: Belknap.

Isin, Engin F. and Patricia K. Wood. 1999. Citizenship and Identity. London: Sage.

Janoski, Thomas. 1998. Citizenship and Civil Society: A Framework of Rights and Obligations in Liberal, Traditional, and Social Democratic Regimes. Cambridge: Cambridge University Press.

Katz, Elihu. 1992. On Parenting a Paradigm: Gabriel Tarde's Agenda for Opinion and Communication. International Journal of Public Opinion Research 4, 80-85.

Kim, Joohoan. 1997. On the Interactions of News Media, Interpersonal Communication, Opinion Formation, and Participation: Deliberative Democracy and the Public Sphere. Dissertation.Com

Kim, Joohoan, Robert O. Wyatt and Elihu Katz.1999. News, Talk, Opinion, Participation: the Part Played by Conversation in Deliberative Democracy. Political Communication 16, 361-385.

Kohn, M. 2000. Language, Power, Persuasion: Toward a Critique of Deliberative Democracy. Constellations 7, 408- 429.

Kymlicka, Will and Wayne Norman. 1995. Return of the Citizen: A Survey of Recent Work on Citizenship Theory. In R. Beiner (ed.), Theorizing Citizenship, 283-322. Albany, NY: State University of New York Press.

Lazarsfeld, Paul F. and Elihu Katz. 1955. The People's Choice. New York: Columbia University Press.

Lewis, Justin. 2001. Constructing Public Opinion. New York: Columbia University Press.

Lippmann, Walter. 1922. Public Opinion. New York: Macmillan. 
Lundquist, Lennart. 2001. Medborgardemokratin och eliterna. Lund: Studentlitteratur.

Milner, Henry. 2001. Civic Literacy: How Informed Citizens Make Democracy Work. Hanover, NH: University Press of New England.

Mouffe, Chantal. 1993. The Return of the Political. London: Verso.

Mouffe, Chantal. 1999. Deliberative Democracy or Agonistic Pluralism? Social Research 66, 745758.

Noelle-Neumann, Elisabeth. 1993. The Spiral of Silence. 2nd ed. Chicago: University of Chicago Press.

Oldfield, Adrian. 1990. Citizenship: An Unnatural Practice? Political Quarterly 61, 177-87.

Peters, John D. 1995. Historical Tensions in the Concept of Public Opinion. In T. L. Glasser and C.T. Salmon (eds.), Public Opinion and the Communication of Consent, 3-32. New York: Guilford Press.

Preston, P. W. 1997. Political/Cultural Identity: Citizens and Nations in a Global Era. London: Sage.

Putnam, Robert D. 2000. Bowling Alone: The Collapse and Revival of American Community. New York: Simon \& Schuster.

Sandel, Michael J. 1996. Democracy's Discontent: America in Search of a Public Philosophy. Cambridge, MA: Harvard University Press.

Sanders, Lynn. 1997. Against Deliberation. Political Theory 25, 3, 347-376.

Schudson, Michael. 1997. Why Conversation Is not the Soul of Democracy. Critical Studies in Mass Communication 14, 4, 297-309.

Sennett, Richard. 1977. The Fall of Public Man. New York: Knopf.

Splichal, Slavko. 1999. Public Opinion: Developments and Controversies in the Twentieth Century. Lanham, MD: Rowman and Littlefield.

Splichal, Slavko, ed. 2001. Public Opinion and Democracy: Vox Populi - Vox Dei? Cresskill, NJ: Hampton Press.

Walzer, Michael .1992. The Civil Society Argument. In C. Mouffe (ed.), Dimensions of Radical Democracy, 89-107. London: Verso.

Warren, Mark E. 1995. The Self in Discursive Democracy. In S. K. White (eds.), The Cambridge Companion to Habermas, 167-200. Cambridge: Cambridge University Press.

Warren, Mark E. 1996. What Should We Expect From More Democracy? Political Theory 24, 241270.

Wilhelm, Anthony G. 2000. Democracy in the Digital Age: Challenges to Political Life in Cyberspace. London: Routledge.

Wyatt, R., Elihu Katz, and J Kim. 2000. Bridging the Spheres: Political and Personal Conversation in Public and Private Spaces. Journal of Communication 50, 1, 71-92. 